\title{
Kadınlarda sakral nöromodulasyonun etkinliği ve yaşam kalitesine etkisi
}

\author{
The efficacy of sakral neuromodulation and effects on quality of life in women \\ Şenol Tonyalı ${ }^{1}$ Hakan Bahadır Haberal ${ }^{2} \quad$ Cenk Yücel Bilen ${ }^{2} \quad$ Ali Ergen $^{2}$ \\ ${ }^{1}$ Türkiye Yüksek İhtisas Eğitim ve Araştırma Hastanesi, Üroloji Kliniği, Ankara, Türkiye \\ ${ }^{2}$ Hacettepe Üniversitesi Tıp Fakültesi, Üroloji Anabilim Dalı, Ankara, Türkiye
}

\section{Öz}

Amaç: Kadın hastalarda sakral nöromodülasyon (SNM) işleminin etkinliğini ve sağlıkla ilişkili yaşam kalitesi üzerine etkisini ortaya koymayı amaçladık.

Gereç ve Yöntem: Hacettepe Üniversitesi Hastanesinde 1999-2016 tarihleri arasında SNM işlemi yapılan hastaların verileri retrospektif olarak değerlendirildi. SNM işlemi başarılı olan ve kalıcı pil yerleştirilen kadın hastalar çalışmaya dahil edildi. Hem SNM hastalarına hem de kontrol grubuna Bristol Female Lower Urinary Tract Symptoms (BFLUTS) anketinin Türkçe geçerliliği yapılmış şekli uygulandı ve BFLUTS'un skorlanmış formuna uyarlandı.

Bulgular: SNM işlemi uygulanan toplam hasta sayısı 35 idi. Bu hastalar içinden testi başarılı olan ve kalıcı pil yerleştirilen toplam 19 kadın hastaya anket formu gönderildi ve ankete cevap veren 9 kadın çalışmaya dahil edildi.

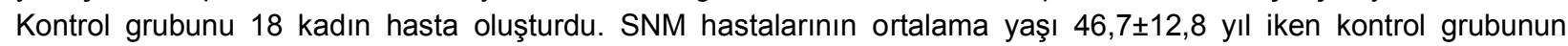
ortalama yaşı 44,2 $\pm 8,2$ yıl olup gruplar arasında yaş açısından anlamlı farklılık bulunmamakta idi $(p=0,544)$. Dolum ve işeme semptomları SNM hasta grubunda daha sık gözlenirken inkontinans semptomları SNM hastaları ve kontrol grubunda benzerdi. SNM hastalarının seksüel fonksiyonlarında kontrol grubundakilere göre bir kötüleşme saptanmadı. SNM hastalarının yaşam kaliteleri kontrol grubuna göre anlamlı olarak azalmış bulundu.

Sonuç: SNM işlemi alt üriner sistem disfonksiyonu (AÜSD) olan hastalarda tercih edilebilecek bir tedavi yöntemidir. SNM işlemi geçiren kadın hastaların idrar kaçırma durumları ve seksüel fonksiyonları aynı yaş grubundaki erişkinler ile benzerlik göstermektedir.

Anahtar Sözcükler: Sakral nöromodülasyon, inkontinans, yaşam kalitesi, seksüel fonksiyon.

\section{Abstract}

Aim: We aimed to determine the efficacy of sacral neuromodulation (SNM) and affects on health-related quality of life in women.

Materials and Methods: The records of patients undergone SNM at Hacettepe University Hospital between 1999 and 2016 were analyzed. Female patients with a successful SNM procedure who were placed permanent battery were included the study. Both the SNM patients and the control group were administered the Turkish validated version of the Bristol Female Lower Urinary Tract Symptoms (BFLUTS) questionnaire and adapted to the scored form of BFLUTS.

Results: In total 35 patients had undergone SNM. Among these patients, a total of 19 female patients who had been tested successfully and were placed permanent batteries were sent a questionnaire and 9 women who answered the questionnaire were included in the study. The control group consisted of 18 female patients. The mean age of the SNM patients was $46.7 \pm 12.8$ years, while the mean age of the control group was $44.2 \pm 8.2$ years. There was no significant difference between the groups in terms of age $(p=0.544)$. Filling and voiding symptoms were more frequent in the SNM patient group, whereas incontinence symptoms were similar in the SNM patients and control group. There was no deterioration in sexual function of SNM patients compared to controls. The quality of life of SNM patients was significantly lower than the control group.

Yazışma Adresi: Şenol Tonyalı

Türkiye Yüksek İhtisas Eğitim ve Araştırma Hastanesi, Üroloji

Kliniği, Ankara, Türkiye

Makalenin Geliş Tarihi: 09.11.2017 Kabul Tarihi: 19.12.2017

218 
Conclusion: SNM would be the choice of treatment for patients with lower urinary tract dysfunction. Urinary incontinence and sexual functions of female patients who underwent SNM treatment are similar to adults of the same age group.

Keywords: Sacral neuromodulation, incontinence, quality of life, sexual function.

\section{Giriş}

Sakral nöromodülasyon (SNM) çeşitli işeme disfonksiyonu durumlarında kullanılan minimal invaziv bir tedavi seçeneğidir. Sakral sinir stimülasyonu (SSS) ile alakalı ilk çalışmalar Schmidt Tanago (1) tarafından yapılmış ve 1988 yılında SSS aletinin yerleştirilmesi işlemi tanımlanmıştır. United States Food and Drug Administration (US-FDA) tarafından 1997 yılında refrakter aşırı aktif mesane ve urgency-frequency sendromu, 1999 yılında ise non-obstrüktif üriner retansiyon tedavisi için onay almıştır (2). FDA tarafından onaylanan endikasyonları dışında SNM'nin fekal inkontinans, kronik pelvik ağrı sendromu ve interstisyel sistit (IS) gibi kronik pelvik taban bozukluklarında da yararlı olduğu gözlenmiştir (3).

Nöromodulasyon migren tipi baş ağrısı, sırt ağrısı, idiyopatik anjina pektoris gibi kronik ağrı durumlarının tedavisinde başarı ile kullanılmaktadır. Is hastalarında SNM tedavisinin erken dönem sonuçları ümit vaat edici olmakla birlikte iyileşmenin kalıcılığı konusunda çelişkili bilgiler mevcuttur ve üriner semptomlar ağrı semptomlarına göre tedaviye daha iyi yanıt veriyor gibi görünmektedir (4).

Bu çalışmada çeşitli hastalıklar nedenli SNM uygulanan hastalarda SNM işleminin etkinliğini ve yaşam kalitesi üzerine etkisini ortaya koymaya çalıştık.

\section{Gereç ve Yöntem}

Etik kurul onayı alındıktan sonra Hacettepe Üniversitesi Hastanesinde 1999-2016 tarihleri arasında SNM işlemi yapılan hastaların verileri retrospektif olarak değerlendirildi. SNM işlemi başarılı olan ve kalıcı pil yerleştirilen kadın hastalar çalışmaya dahil edildi. Kontrol grubu olarak üroloji polikliniğine alt üriner sistem semptomları dışındaki yakınmalarla başvuran benzer yaş grubundaki kadın hastalar seçildi. Hem SNM hastalarına hem de kontrol grubuna Bristol Female Lower Urinary Tract Symptoms (BFLUTS) anketinin Türkçe geçerliliği yapılmış şekli uygulandı ve BFLUTS'nin skorlanmış formuna uyarlandı $(5,6)$. Değerlendirilen parametreler hasta demografik bilgileri, SNM işlemi tarihi, SNM yapılma nedeni ve anket sonuçlarından oluşmakta idi.

Bristol Female Lower Urinary Tract Symptoms (BFLUTS) anketi

BFLUTS anketi kadınlarda AÜSS geniş bir yelpazede değerlendirmek ve ölçmek için ilk kez Birleşik Krallık'ta geliştirilen bir ankettir. Bu anket inkontinans, diğer
AÜSS, seksüel hususlar ve yaşam kalitesine dair sorular içermektedir. Orijinal BFLUTS anketinde 19'u semptom, 4'ü seksüel fonksiyon ve 11'i yaşam kalitesi ile ilgili toplam 34 soru bulunmaktadır $(6,7)$. BFLUTS'un skorlanmış formunda ise inkontinans (BFLUTS-IS), işeme (BFLUTS-VS) ve dolum (BFLUTS-FS) semptomlarına dair 3 alt ölçek ve ek olarak seksüel fonksiyon (BFLUTS-seks) ve yaşam kalitesine (BFLUTSQoL) dair 2 alt ölçek bulunmaktadır (6).

\section{Cerrahi prosedür}

Tüm hastalara InterStim ${ }^{\mathrm{TM}}$ (Medtronic Inc., Minneapolis, MI, USA) dişli kılavuz implantasyonu floroskopi yardımı ile çoğunlukla genel anestezi altında perkütan yöntem ile yapıldı. İmplantasyonda tek taraflı sakral S3 sinir kökü tercih edildi. Sinyal jeneratörü kalçanın üst dış kısmına yerleştirildi.

\section{Bulgular}

Belirtilen tarihler arasında SNM işlemi uygulanan hasta sayısı 35 olarak saptandı. Bu hastalar içinden testi başarılı olan ve kalıcı pil yerleştirilen toplam 19 kadın hastaya anket formu gönderildi ve ankete cevap veren 9 kadın çalışmaya dahil edildi. Kontrol grubunu 18 kadın hasta oluşturdu. Anket sırasında SNM hastalarının ortalama yaşı $46,7 \pm 12,8$ yıl iken kontrol grubunun ortalama yaşı $44,2 \pm 8,2$ yıl olup gruplar arasında yaş açısından anlamlı farklılık bulunmamıştır $(p=0,403)$. Dokuz hastadan 6'sı nörojen mesane, 3'ü ise üriner retansiyon nedenli SNM işlemi geçirmiş idi. SNM hastaları ve kontrol grubunun Bristol Female Lower Urinary Tract Symptoms anketinin sonuçları Tablo-1'de verilmiştir. Dolum ve işeme semptomları SNM hasta grubunda daha sık gözlenirken inkontinans semptomları SNM hastaları ve kontrol grubunda benzerdi. SNM hastalarının seksüel fonksiyonlarında kontrollere göre bir kötüleşme saptanmadı. SNM hastalarının yaşam kaliteleri kontrol grubuna göre anlamlı olarak azalmış bulundu.

Tablo-1: Bristol Female Lower Urinary Tract Symptoms (BFLUTS) Anketi Sonuçlarının Karşılaştııılması.

\begin{tabular}{lccc}
\hline & SNM Grubu & Kontrol Grubu & p değeri \\
\hline BFLUTS-FS & $5,2 \pm 3,4$ & $2,6 \pm 1,4$ & 0,023 \\
BFLUTS-VS & $4,7 \pm 3,9$ & $1,2 \pm 1,5$ & 0,012 \\
BFLUTS-IS & $3,0 \pm 3,8$ & $2,0 \pm 1,5$ & 1,000 \\
BFLUTS-SF & $1,2 \pm 1,5$ & $0,3 \pm 0,7$ & 0,232 \\
BFLUTS-QoL & $5,4 \pm 4,0$ & $1,5 \pm 1,4$ & 0,027 \\
\hline
\end{tabular}

FS: Filling symptom; VS: Voiding symptom; IS: Incontinence symptom SF: Sexual function; QoL: Quality of life 


\section{Tartışma}

İşeme normalde eksternal üretral sfinkter ve pelvik taban kaslarının istemli gevşemesi ile başlatılır. Pelvik taban disfonksiyonu pelvik tabanın aşırı spastisitesi ve hiperaktivitesi ile birlikte fonksiyonel detrüsör sfinkter dissinerjisine yol açabilir. Böylece zor işeme ve çeşitli derecelerde üriner retansiyon ortaya çıkabilir. Fonksiyonel üriner retansiyon başlarda psikojenik olarak kabul edilmekte iken pelvik taban spastisite ve hiperaktivitesine sekonder geliştiği gösterilmiştir (8) SNM'nin refrakter idiyopatik üriner retansiyonda etkili olduğu ortaya konmuştur (8).

SNM başlangıçta nörojenik alt üriner sistem disfonksiyonunda (AÜSD) bir seçenek olarak görülmezken yapılan çalışmalarda bu tür hastalarda da efektif bir tedavi seçeneği olduğu ortaya konulmuştur $(9,10)$. AÜSD'si olan multipl skleroz hastaları ile yapılan bir çalışmada SNM sonrası yapılan takiplerde işeme parametrelerinin hepsinde anlamlı gelişme olduğu bildirilmiştir (11).

SNM işleminin nörojenik non-obstrüktif üriner retansiyonda da işe yarayabileceği gösterilmiştir. Inkomplet spinal kord lezyonu olan hastalarla yapılan bir çalışmada hastaların \% 40'ının ilk basamak SNM işlemine cevap verdiği bildirilmiştir (12).

Aşırı aktif mesane ve üriner retansiyon gibi alt üriner sistem semptomları kişilerin günlük aktivitelerini ve sosyal hayatlarını aşırı derecede etkileyebilir. Çeşitli çalışmalarda SNM'nin hasta yaşam kalitesi üzerine etkileri değerlendirilmiştir (13-15). Cappellano ve ark. (13) tarafından yapılan çalışmada SNM'nin urge inkontinansta efektif bir tedavi yöntemi olduğu ve hasta yaşam kalitesine pozitif etki ettiği gösterilmiştir. Ayrıca hastaların günlük idrar kaçırma epizodlarının da azaldığı gösterilmiştir. Bu çalışmamızda da SNM hastaları ile kontrol grubu arasında inkontinans semptomları arasında anlamlı farklılık izlenmemiştir.

Başka bir uluslararası, çok merkezli, randomize kontrollü çalışmada Beck Depresyon anketi ve Medical Outcomes Study Short-From 36 kullanılarak refrakter urge inkontinans, non-obstruktif üriner retansiyon veya urgency/frequency'si olan 89 hastanın depresyon durumları ve sağlık ile ilişkili yaşam kaliteleri değerlendirilmiştir (14). Bu çalışmanın sonuçlarına göre SNM öncesi hastalarda saptanabilen derecelerde depresyon ve azalmış yaşam kalitesi tespit edilmiş, SNM tedavisi sonrası hastaların hem depresyon hem de sağılık ile ilişkili yaşam kalitelerinde anlamlı iyileşmeler gözlenmiştir (14). Bizim çalışmamızda SNM hastaları ile kontrol grubu hastalarının seksüel fonksiyonları arasında anlamlı bir farklılık izlenmezken SNM hastalarının yaşam kalitelerinin kontrollere göre daha kötü olduğu gösterildi.

\section{Kısıtıııklar}

Bu çalışmanın kısıtlılığı olarak ilk başta az hasta sayısı gösterilebilir. Fakat literatüre bakıldığında SNM ile ilişkili çalışmaların benzer şekilde az hasta sayıları ile yapıldığı görülmektedir. Bir diğer kısıtılık ile SNM hastalarının preoperatif anketlerinin olmamasıdır. Yıllık yapılan vaka sayısının azlığı ve hastaların dahil edilme periyodunun uzunluğu çalışmanın tamamen prospektif olarak yürütülmesine imkan vermemektedir.

\section{Sonuç}

SNM işlemi AÜSD olan hastalarda tercih edilebilecek bir tedavi yöntemidir. SNM işlemi geçiren kadın hastaların idrar kaçırma durumları ve seksüel fonksiyonları aynı yaş grubundaki erişkinler ile benzerlik göstermektedir. Geniş hasta grupları ile yapılacak prospektif randomize kontrollü çalışmalar bu konudaki bilgi birikimimize katkı sağlayacaktır.

\section{Kaynaklar}

1. Tanagho EA, Schmidt RA. Electrical stimulation in the clinical management of the neurogenic bladder. J Urol 1988;140(6):13319.

2. Banakhar M, Hassouna M. Sacral neuromodulation for genitourinary problems. Prog Neurol Surg 2015;29:192-9.

3. Van Kerrebroeck PE, Marcelissen TA. Sacral neuromodulation for lower urinary tract dysfunction. World J Urol 2012;30(4):44550.

4. Zabihi N, Mourtzinos A, Maher MG, Raz S, Rodriguez LV. Short-term results of bilateral S2-S4 sacral neuromodulation for the treatment of refractory interstitial cystitis, painful bladder syndrome, and chronic pelvic pain. Int Urogynecol $\mathrm{J}$ Pelvic Floor Dysfunct 2008;19(4):553-7.

5. Gokkaya CS, Oztekin CV, Doluoglu OG, et al. Validation of Turkish version of Bristol Female Lower Urinary Tract Symptom Index. J Clin Anal Med 2012;3(4):415-8.

6. Brookes ST, Donovan JL, Wright M, Jackson S, Abrams P. A scored form of the Bristol Female Lower Urinary Tract Symptoms questionnaire: Data from a randomized controlled trial of surgery for women with stress incontinence. Am J Obstet Gynecol 2004;191(1):73-82

7. Jackson S, Donovan J, Brookes S, Eckford S, Swithinbank L, Abrams P. The Bristol Female Lower Urinary Tract Symptoms questionnaire: Development and psychometric testing. Br J Urol 1996;77(6):805-12.

8. Aboseif S, Tamaddon K, Chalfin S, et al. Sacral neuromodulation in functional urinary retention: An effective way to restore voiding. BJU Int 2002;90(7):662-5. 
9. Kessler TM, La Framboise D, Trelle S, et al. Sacral neuromodulation for neurogenic lower urinary tract dysfunction: Systematic review and meta-analysis. Eur Urol 2010;58(6):865-74.

10. Wollner J, Krebs J, Pannek J. Sacral neuromodulation in patients with neurogenic lower urinary tract dysfunction. Spinal Cord 2016;54(2):137-40.

11. Engeler DS, Meyer D, Abt D, Muller S, Schmid HP. Sacral neuromodulation for the treatment of neurogenic lower urinary tract dysfunction caused by multiple sclerosis: A single-centre prospective series. BMC Urol 2015;15(2):105.

12. Lombardi G, Musco S, Celso M, Del Corso F, Del Popolo G. Sacral neuromodulation for neurogenic non-obstructive urinary retention in incomplete spinal cord patients: A ten-year follow-up single-centre experience. Spinal Cord 2014;52(3):241-5.

13. Cappellano F, Bertapelle $P$, Spinelli $M$, et al. Quality of life assessment in patients who undergo sacral neuromodulation implantation for urge incontinence: An additional tool for evaluating outcome. J Urol 2001;166(6):2277-80.

14. Das AK, Carlson AM, Hull M, Group USM-S. Improvement in depression and health-related quality of life after sacral nerve stimulation therapy for treatment of voiding dysfunction. Urology 2004;64(1):62-8.

15. Foster RT Sr, Anoia EJ, Webster GD, Amundsen CL. In patients undergoing neuromodulation for intractable urge incontinence a reduction in $24-\mathrm{hr}$ pad weight after the initial test stimulation best predicts long-term patient satisfaction. Neurourol Urodyn 2007;26(2):213-7. 